\title{
Estimation of Placental Thickness in Pregnant Sudanese Women
}

\author{
Muna Ali ${ }^{1}$, A. H. A. Bakry, 2, 3, 4*, Asma Elamin ${ }^{1}$, Shazaly N. Khojaly ${ }^{1}$, Mohamed Yousef ${ }^{1}$, \\ Doha Abdo M. Abdo ${ }^{1}$, Auis Bashir ${ }^{1}$ \\ ${ }^{1}$ Sudan University of Science and Technology, College of Medical Radiological Science, Khartoum, Sudan \\ ${ }^{2}$ Radiology Department, Elnileen Diagnostic Medical Center, Khartoum, Sudan \\ ${ }^{3}$ Radiology Department, Antalya Medical Center, Khartoum, Sudan \\ ${ }^{4}$ National university-Sudan, Faculty of Radiography \& Medical Imaging, Khartoum, Sudan
}

\begin{abstract}
A descriptive study aimed to investigate the relationship between the placental thickness and estimated fetal weight in normal Sudanese pregnant women in order to develop a linear equation that can be used to estimate the placental thickness. The data collected in Omdurman Maternity Hospital (Omdurman) from November 2014 to February 2015; Fifty-Two pregnant women in second and third trimesters were scanned by ultrasound machine Toshiba-power vision-6000. Placental thickness was measured in a longitudinal section at the point of insertion of the umbilical cord. the variables used to establish this study was mother age, BPD, fetal Age, AC, and estimated fetal weight which having mean \pm SD of (26.39 $\pm 6 \mathrm{yrs}),(64.23 \pm 19.9 \mathrm{~mm}),(26.82 \pm 7.56 \mathrm{age}),(235.4 \pm 90.35 \mathrm{~mm})$ and $(1497.7 \pm 1387.4 \mathrm{gm})$ respectively. And the mean thickness of placenta was $(32.9 \pm 9.2 \mathrm{~mm})$. A strong direct correlation was noted between all parameters and placental thickness.
\end{abstract}

Keywords: Fetal weight, Placental Thickness, Pregnant Women, Gravida.

\section{Introduction}

The placenta is a vascular structure by which an unborn child is attached to its mother's uterine wall and through which respiratory gas and metabolic exchange occurs. The placenta is formed in part from maternal tissue and in part from embryonic tissue. The embryonic portion of the placenta consists of the chorionfrondosum, whereas the maternal portion is composed of the area of the uterine wall called the decidua basalis, into which the chorionic villi penetrate. Blood does not flow directly between these two portions, but because their membranes are in close proximity, certain substances diffuse readily. When fully formed, the placenta is a reddish brown oval disc with a diameter of 15 to $20 \mathrm{~cm}$ and a thickness of $2.5 \mathrm{~cm}$, It weighs between 500 and $600 \mathrm{~g}$, about one sixth as much as the fetus. (Graaff 2001).

As a result of the continuous growth of the fetus and expansion of the uterus, the placenta also enlarges. Its increase in surface area roughly parallels that of the expanding uterus and throughout pregnancy it covers approximately 15 to $30 \%$ of the internal surface of the uterus. The increase in thickness of the placenta results from arborization of existing villi and is not caused by further penetration into maternal tissues. So Placental thickness is closely related to fetal wellbeing and may be a key factor in perinatal outcome. (Sadler 2004).

The use of ultrasound to evaluate the placenta is routine among the majority of pregnant women. A wide range of pregnancy complications result from abnormal placental development, including preeclampsia, intrauterine growth retardation (IUGR) and abruption. Other placental abnormalities, such as placenta previa, percreta or vasa previa, may cause major maternal and fetal complications. Timely recognition of these abnormalities can lead to improve management of pregnancy and delivery. Thus, careful examinations of the placenta by ultrasound can contribute directly to enhance patient care and improve outcomes. (Rumack et al 2011).

Before the availability of the ultrasound, manual examination of the maternal abdomen was the only approach that could be used to estimate fetal size. The physical examination, however, provides only a general approximation of fetal weight because the palpated dimensions of the uterus are affected by several factors other than fetal size, including amniotic fluid volume, placental bulk, presence of fibroids and maternal obesity. Sonographic measurements of the fetus provide information about fetal age and growth. These data are used to assign gestational age, estimated fetal weight and diagnose growth disturbance. The measurements of fetal body parts provide a direct way of assessing fetal size. Numerous formulas have been published for estimating fetal weight from one or more of these fetal body measurements: head (bi-parietal diameter BPD or head circumference HC), abdomen (abdominal diameter AD or abdomen circumference, AC), and femur length (FL).

Estimation of fetal weight, on its own and in relation to the gestational age, can influence obstetric management decisions concerning the timing and route of delivery. Early delivery may benefit a fetus that is small for dates. Such a fetus may be inadequately supplied by its placenta with oxygen and nutrients and therefore may do better in the care of neonatologist than in uterus. When the fetus is large, cesarean section may be the preferred route of delivery, particularly in pregnancies complicated by maternal diabetes. In view of these considerations, fetal measurements should be a component of every complete obstetric sonogram. (Rumack et al 2011). 


\section{International Journal of Science and Research (IJSR) \\ ISSN (Online): 2319-7064}

Index Copernicus Value (2013): 6.14 | Impact Factor (2015): 6.391

\section{Material and Method}

This descriptive study includes fifty two Sudanese pregnant women in second and third trimesters came to the ultrasound department for regular checkup. The selected women were attending with viable singleton pregnancy. Pregnant women with hypertension $(\mathrm{PIH})$, diabetes mellitus, and history of previous intrauterine growth retardation (IUGR), congenital malformation, twin gestation, and placental anomalies were excluded from this study. Ultrasound examinations is done using ultrasound machine Toshiba-power vision-6000, transabdominal convex transducer with frequency of 3.5 $\mathrm{MHz}$ and ultrasound gel. During the ultrasound examination BPD and abdomen circumference (AC). The placental thickness was measured in longitudinal section at the point of umbilical cord insertion. Fetal age was estimated by measuring biparietal diameter (BPD). Other variables including maternity age, gravidity, were also measured. Statistical analysis was performed and the placental relationship with other variables were done as follow:

\section{Result Presentation}

Table 1: Descriptive statistics of the maternity age, gravida, fetal age and weight and placental thickness

\begin{tabular}{|c|c|c|}
\hline Variables & Mean & $\begin{array}{c}\text { Std. } \\
\text { Deviation }\end{array}$ \\
\hline Mother age years & 26.39 & 6.0 \\
\hline Gravida & 1.64 & 0.841 \\
\hline BPD (mm) & 64.23 & 19.9 \\
\hline Placental Thickness (mm) & 32.9 & 9.2 \\
\hline Fetal Age (weeks) & 26.82 & 7.56 \\
\hline AC (mm) & 235.4 & 90.35 \\
\hline Estimated Fetal Weight (gm) & 1497.7 & 1387.4 \\
\hline
\end{tabular}

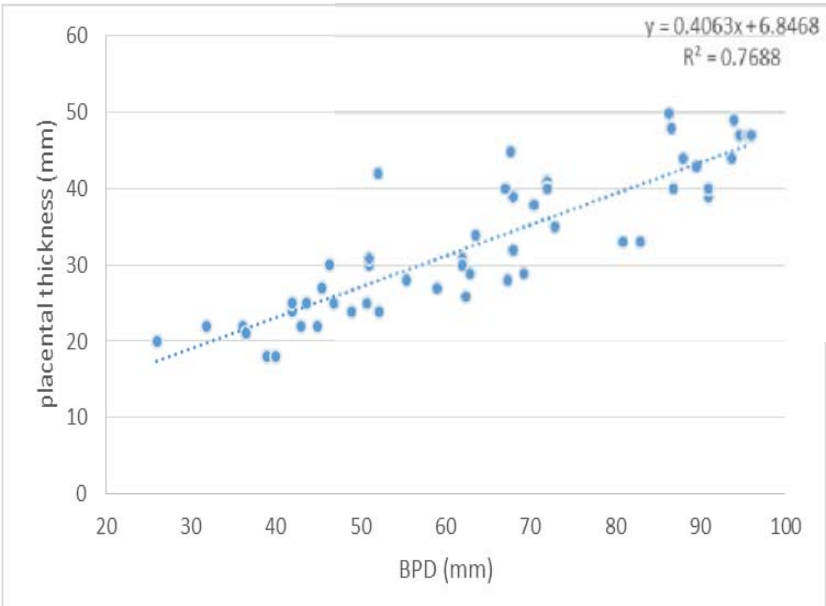

Figure 1: A Direct relationship between placental thickness and bipartial distance

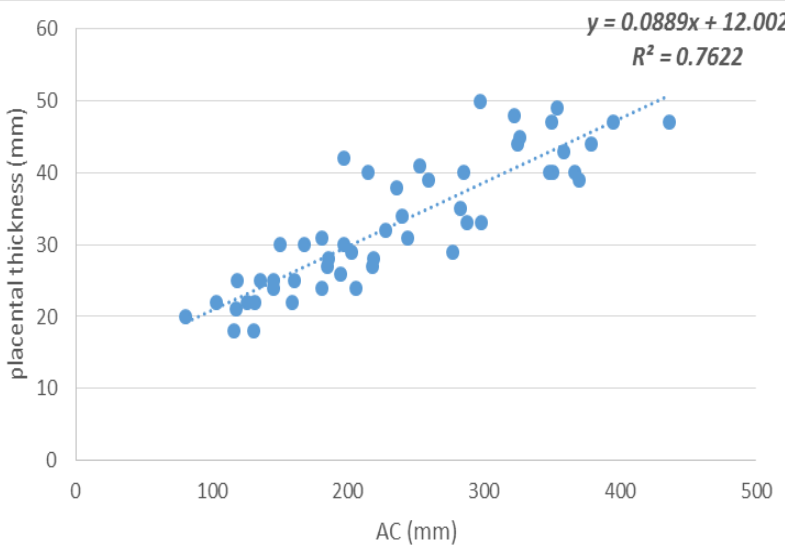

Figure 2: Demonistrate the relation between the placental thickness and abdominal circuferance

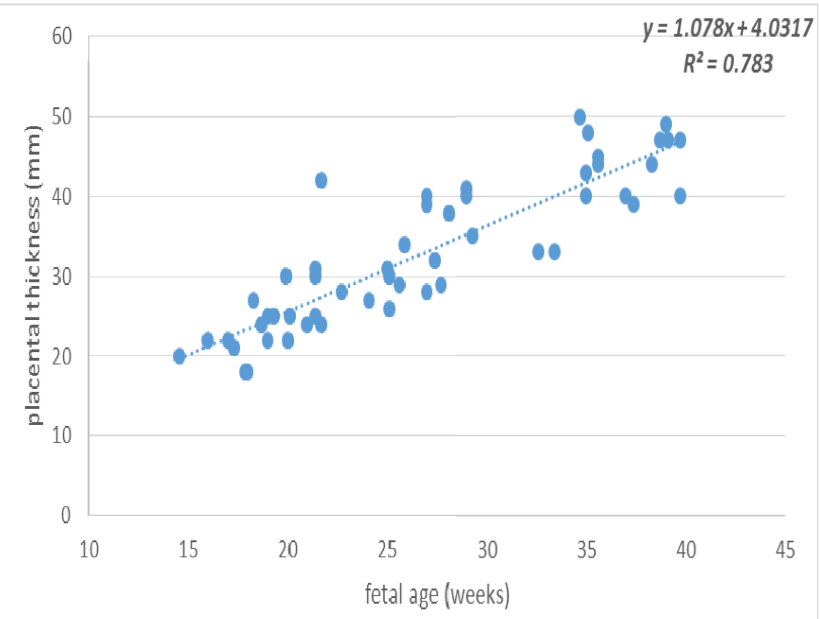

Figure 3: The relation between the placental thickness and fetal age in weeks

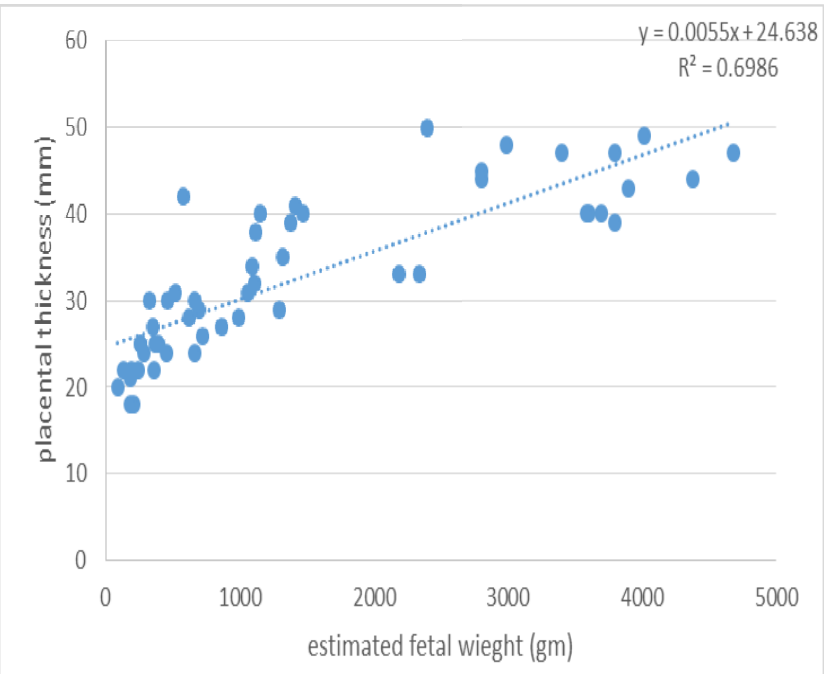

Fig. 4: Showed the placental thickness and etimated fetal wieght

\section{Discussion}

The purpose of this study was to investigate the relationship between the placental thickness and estimated fetal weight in normal Sudanese pregnant women. The research includes 52 pregnant women. the variables used to establish this study 


\section{International Journal of Science and Research (IJSR) \\ ISSN (Online): 2319-7064}

Index Copernicus Value (2013): 6.14 | Impact Factor (2015): 6.391

was mother age, BPD, fetal Age, AC, and estimated fetal weight which having mean \pm SD of (26.39 $\pm 6 \mathrm{yrs})$, $(64.23 \pm 19.9 \mathrm{~mm}),(26.82 \pm 7.56$ age $),(235.4 \pm 90.35 \mathrm{~mm})$ and $(1497.7 \pm 1387.4 \mathrm{gm})$ respectively. And the mean thickness of placenta was $(32.9 \pm 9.2 \mathrm{~mm})$.

The study showed that there is a direct linear relationship between placental thickness and fetal age as shown in figure 4-3 and there is strong positive correlation between them where $y=1.078 x+4.0317, R^{2}=\mathbf{0 . 7 8 3}$; for fetal weight, and $\boldsymbol{y}=\mathbf{0 . 0 0 5 5} \boldsymbol{x}+\mathbf{2 4 . 6 3 8}, \boldsymbol{R}^{2}=\mathbf{0 . 6 9 8 6}$, for estimated fetal age by ultrasound examination. These results establish that there is a firmly fixed increase in placental thickness (PT) with the increase of fetal age, which typically go with those studies done by Ohagwu et al 2009, Hammad 2008 and Elamin 2012, all studies concurred in that the placental thickness increase with the increase of fetal age.

The relation between the placental thickness and the biparital distance was investigated where strong direct relationship were noted; placental thickness increased by $0.4063 \mathrm{~mm}$ for every on $\mathrm{mm}$ increment in biparital distance, $y=0.4063 x=6.8468, R^{2}=0.7688$.

The study found that the estimation of fetal weight-which based on BPD and AC- have positive significant correlation with Placental thickness. Both are increasing continuously with fetal age. The positive significant correlation between them with $(\mathrm{R}=0.836)$ and $(\mathrm{p}=0.01)$ and the placental thickness increased by $0.0055 \mathrm{~mm}$ for every one gm increment in estimated fetal weight using BPD and AC in ultrasound measurement. This result is similar to Nigerian study done by Abo et al (2009) in Nigeria. Both studies found positive significant correlation between Placental thickness and estimated fetal weight.

The above result can lead the Placental thickness to be an initial parameter for fetal weight estimation. This help to know the normality of fetal weight or predicting any abnormalities such as intrauterine growth retardation (IUGR). It has been realized that with the same placental thickness there are different estimations of fetal weight. We think that is due to normal variations between pregnancies and due to small volume of cases included in the study. The study showed that there is no relation between Placental thickness and maternity age. Also there is no relation between placental thickness and the gravidity.

\section{References}

[1] Graaff. V. D, (2001), Human Anatomy.6 ed, The McGraw-Hill Companies. U.S.A, 754-790.

[2] Hammad, YH, (2008), Measurements of Placental Thickness by Ultrasound in Third Trimester, Sudan University of Science and Technology. Khartoum.

[3] Ohagwu CC, (2009), Relationship between Placental Thickness and Growth Parameters in Normal Nigerian Fetuses, African Journal of Biotechnology, 8: 133- 138.

[4] Rubin. E \& Farber. J.L, (1999), Pathology, 3ed, Lippencott-Raven publisher, Philadelphia, 1016-1024.
[5] Rumack. Carol. M, 2011, Diagnostic Ultrasound, 4th ed, Elsevier Mosby, Philadelphia, 1502.

[6] Sadler. T.W. 2004, Medical Embryology Langman, 9th ed, Lippincott William \& Wikins, 117-147.

[7] Scanlon. Valerie C. \& Sanders. T, 2007, Essentials of anatomy and physiology, 5th ed. F. A. Davis Company, Philadelphia, 480.

[8] Abo,po, 2009 ,Correlation Between Placental Thickness and Estimated Fetal Weight in Nigerian Women, Ibnosina Journal of Medicine and Biomedical Science, 3: $80-85$

[9] Chie.L, \& Levine.D, 2006, Ultrasound Clinics, Elsevier Saunders, USA, 303-319.

[10]Kurjak.A， Chervenak.F.A， 2006, Donald School Textbook of Ultrasound in Obstetrics and Gynecology, Taylor \& Francis e-Library, London, 259-268.

\section{Author Profile}

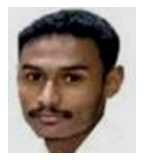

Mr. Abdoelrahman Hassan Ali Bakry (Sudan) received the (B.Sc.) and (M.Sc.-1) in radiotherapy technology from College of Medical radiological Science, Sudan University of Science and Technology in 2013 and 2015 respectively.M.Sc.-2 (student) Diagnostic Radiology Technology, National university (Sudan)-2016. During 2013 up to date, he is staying in College of Medical radiological Science, Sudan University of Science and Technology, Radiology Department, Antalya Medical Center and Elnileen Diagnostic Medical Center; also he has been active in Computerized Texture Analysis, Radiotherapy-Oncology, and Diagnostic Radiology, Medical physics, ultrasound and Nuclear Medicine researches. Now he is lecturer at SUST also (2016).

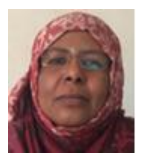

Dr. Asma Ibrahim Ahmed (Sudan), awarded the B.Sc. in diagnostic radiology technology (1996), M.Sc. in medical ultrasound (2005, SUST), as well as $\mathrm{PhD}$ degree in diagnostic radiology (SUST, 2012), during 1998 she has been working as teaching assistant at COMRS, SUST, as well as lecturer, and assistant professor in 2005, and 2012 respectively. She has been active in diagnostic radiology, medical ultrasound researches.

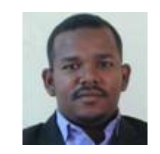

Mr. Shazaly Nader Khojaly Mansour (Sudan) received the (B.Sc.) in diagnostic radiology technology and (M.Sc.) in medical ultrasound imaging from College of Medical radiological Science, Sudan University of Science and Technology in 2011 and 2015 respectively. He has been working as teaching assistant and lectural at COMRS, SUST during 2012 and 2016 respectively. And working as specialist radiology and ultra-sonographer in jarash specialist international hospital. During 2013 up to date also he has been active in Diagnostic Radiology, Medical physics, ultrasound and Nuclear Medicine researches. 